Publisher homepage: www.universepg.com, ISSN: 2663-7820 (Online) \& 2663-7812 (Print)

https://doi.org/10.34104/cjbis.021.049059

Canadian Journal of Business and Information Studies Journal homepage: http://www.universepg.com/journal/cjbis

Canadian Journal of Business and Information Studies
Canadian Journat of Business and Information Studies

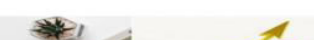

\title{
Optimizing Organizational Overall Performance, the Use of Quantitative Choice of HR in Carrier Quarter Enterprise of Bangladesh
}

\author{
Hasan M Sami* \\ School of Business, Canadian University Bangladesh, Dhaka, Bangladesh. \\ *Correspondence: samifrnds90@gmail.com (Hasan M Sami, Senior Lecturer, School of Business, Canadian University \\ Bangladesh, Dhaka, Bangladesh).
}

\begin{abstract}
Organization's most important purpose is to reap performance and effectiveness thru productiveness and powerful control. It's visible that even though the paramount significance of AI, records technological knowhow and analytics are governing the prevailing international activity dominion however nonetheless the dearth of powerful HR is felt and found in the course of the company system. A human useful resource wishes to be well certified, converted and powerful for being a success entity of any company. In this studies paper we've on the whole targeted on enforcing diverse quantitative choice strategies the use of SPC and K nearest neighbor set of rules for great viable choice system. The paper makes a specialty of carried out gadget gaining knowledge of attitude of $\mathrm{KNN}$ as a foundation of type for efficaciously deciding on personnel on the idea of theoretical and market place reliable criteria. The paper eventually solutions to healthy if the study's findings have become sufficiently excellent sufficient for the company in phrases of monetary proofs or value advantage technique.
\end{abstract}

Keywords: K-Nearest, HRIS, SME, Process Expert, Motivation, Performance Management, and Point of Interest.

\section{INTRODUCTION:}

Selecting a powerful team of workers has the number one fulfillment aspect for any company for the reason that delivery of civilization. It's visible that human sources nice and efficiency applies to utmost beneficiary for any company. Smith et al. (2007) has referred that HR choice system thru powerful bias and validity has been of maximum significance. Our techniques could endorse how different factors inclusive of criteria-primarily based totally choice techniques thru efficiency bias and validity technique could get frequent as a technique for HR choice. In Smith et al. (2007) its visible that even though take a look at developers, employers and coverage makers efficaciously respect a biased and legitimate answer

UniversePG I www.universepg.com system to indicate about the great appearing issue, however our technique could permit tons justifiable elements as center concepts for reading the overall performance aspect as a critical characteristic for organizational advantage. In accordance to Taguchi's concept of CRD (Critical Research Diagram), wherein human sources are referred as controllable elements and project complexities as unpredictable noise elements.

Tsai et al. (2003) recommended a tons-improvised technique in connection with value shape for choice of human sources. In truth the aspect associated with value discount is calling at most effective one attitude of Human useful resource choice, while worker overall performance improvement problems, organizational 
exercise views and diverse different elements had been overlooked. In our studies paper we might attempt to examine the end result primarily based totally on all HR choice attitude priorly. Nasir et al. (2013) have recommended that discriminant evaluation elements truly justified with advantage presenting and social repute success are without delay correlated so that it will make best recommendations. Our thoughts contradict within side the context that HR choice system in widespread has plenty of attributive elements that is based on natural evaluative recommendations and proportional statistical recommendations for powerful HR choice system. Huang et al. (2004) have recommended that the use of HRIS, AI could make powerful and correct human like judgement, however out techniques endorse how an evaluative and statistical system can create powerful recommendations for HR choice.

In accordance to Swanson (Swanson, 1995) overall performance stays the important thing parameter for human useful resource control on the subject of organizational purpose success. In accordance to Swanson, it's found that overall performance signs are powerful below organizational, system and man or woman phrases. In our studies system, its visible that so that it will obtain organizational goals, the great technique is to obtain accuracy overall performance on the subject of system primarily based totally parameters and team of workers nice characteristic improvement in phrases of overall performance measures. Our studies system could hence listen upon the enormous improvement of every problem related to Human Resource Selection system below the subject of Organizational improvement.

\section{Literature Review}

Smith et al. (2007) recommended that validity and bias stay a critical constituent for HR choice system. In addition to concerns concerning take a look at validity and take a look at bias, checks are maximum beneficial after they permit for choice selections that decrease choice mistakes and keep away from unfavorable effect (Aguinis et al., 2007). In accordance to Smith et $a l$, its visible that such an integrative framework could offer a beneficial decision-making device thru which choice devices will be evaluated (Goldstein et al.,
2002) earlier than they're certainly used to make selections primarily based totally on psychometric problems across the prediction of applicants' activity overall performance in addition to value-primarily based totally concerns on the team, organizational, and societal ranges related to expected unfavorable effect (Goldstein et al., 2002).

The typical motivation closer to bias-primarily based totally choice mistakes according to Aguinis et al. (2005) is in particular noteworthy for the reason that an end of no or small bias can be because of numerous methodological and statistical artifacts that lessen pattern-primarily based totally impact sizes extensively on the subject of their populace counterparts. According to Tsai et al. (2003), it's visible that CRD performs a critical function for HR choice. The studies system has followed Taguchi parameter of company overall performance based upon Human aspect as controllable variable and project complexities as unpredictable elements (Hoque et al., 2020). Tsai et al. (2003) efficaciously used CRD with Taguchi parameter as a critical benchmark for human useful resource choice as a degree of organizational overall performance aspect. Through using this technique, Tsai et al. (2003) have applied discount in assignment value and duration. Our studies efficaciously make a specialty of assignment value discount and time optimization as a number one problem however incredibly relenting on the entire component of Human Resource overall performance now no longer most effective at the aspect of HR choice.

Although Nasir et al. (2013) recommended that discriminant aspect is incredibly relative to expert activity positions however our studies is precisely targeted closer to productiveness improvement for business processes, subsequently this paper will contain relative improvement elements for lowly knowledgeable personnel and their overall performance characteristic and control system utility techniques thru gadget gaining knowledge of processes. Although Fishers technique with kernel utility (Mika et al., 1999) has excessive influences however in relation to analyze system and studies query our studies will take a tons-diverted direction to take a look at a powerful system derivation thru studies propositions and studies pattern checks. The effect aspect of studies system evaluation receives 
risen from Human like questioning aspect. Our studies system allocates the same style of human like questioning for HR choice system. Primarily as our studies is deriving organizational overall performance thru HCI improvement we clearly don't depend on the elements of Human Like questioning mechanisms which fits wonderful for ANN \& biased RNN according to Huang et al. (2004). For nonlinear approximations its visible that ANN makes very powerful prediction recommended through Huang et al. (2004), however in truth, our studies system used tons simpler technique to indicate comparative evaluation and consecutive improvement processes. Based on Kavanagh et al. definition, the human useful resource records system (HRIS) refers back to the system of acquire, store, manipulate, analyze, retrieve, and distribute pertinent records concerning a company's human sources. A success HRIS facilitates to perform all features of human sources helping the strategic implementation of human sources.

Walker, (1993) factors out that due to the quick modifications withinside the enterprise environment, the call for certified employees has expanded so that it will benefit control performance and overall performance. Our studies system lets in to efficaciously dominate the pattern for correctly matching the precise companies alongside their overall performance thru confusion matrix system that elaborates right technique for overall performance improvement. Using Swanson's, (1995) view factor for elaboration, overall performance of human sources stays the important thing concept for organizational improvement.

Theoretical Framework - In relation to organizational performance development, there are three anchors which creates firm benefit at its most.

HR Efficiency - When the HR packages and practices are introduced thru frugal use of sources inclusive of time, cash and labor (Boudreau \& Ramstad 2004).

HR Effectiveness - How to make the HR practices and packages useful in phrases of variation wishes of various elegance of workforce's gift withinside the company for natural organizational advantage (Boudreau \& Ramstad, 2004).

UniversePG I www.universepg.com
HR Impact - Justification of HR packages and practices that makes the best fine impact in strategic and organizational goals (Boudreau \& Ramstad, 2004). In order to make those 3 elements of HR successful, our studies manner might observe via an essential query of characteristic alternatives that changed into validated as a characteristic to idea supplied via Voca \& Havolli, (2019). In accordance Voca \& Havolli, (2019) 3 elements make powerful contribution in the direction of organizational overall performance. Although our studies paper doesn't recognition on motivational aspect evaluation however thinking about a unique motivational grade via peer reviewed surveys might be taken into consideration for our number one studies motive. Our number one surveys might display the best attributes for 2 employees. It's visible that the maximum typical elements stay as skillset and applicable experience. Using those 3 elements as number one key factors for attention our recruitment and choice manner must be carried out. For our studies motive hence, we've got devoted very precise fashions of choice manner. Entry Level: Horwitz et al. (2000) recommended that for an access degree employee in relevance to his/her process function and role of applicability, its visible that motivation makes the maximum fine impact. In relation to technical element of the process function or role it observed that, an access degree employee wishes to have at the least $40 \%$ motivation in the direction of their painting's overall performance and tasks. The final must get brought to skillset characteristic for access degree workers.

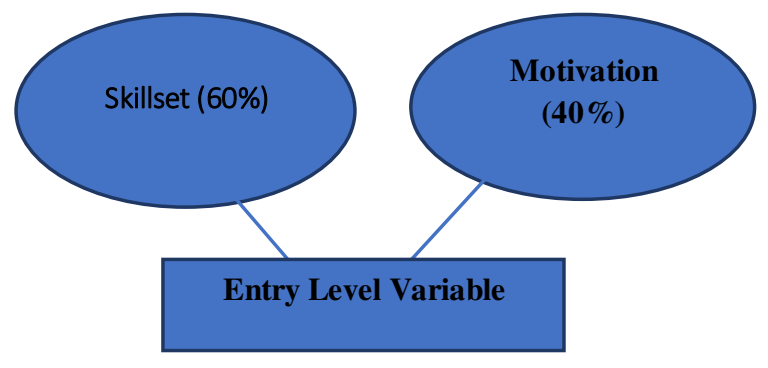

Fig 1: Basic selection criteria.

Through inquisitive wondering and version studies survey suggestions (Gault et al., 2000; Gupta et al., 2010; Gault et al., 2010) have been formulated to recognize the significance of internships and its relevance toward activity success. In maximum of the 
University packages for Business School graduates it observed that an internship is a have to requirement for his or her commencement completion. Gault et al. (2010) recommended that as internships check with powerful improvement of scholar employment marketability therefore maximum college students require to finish which will recognize how the taught talents ought to get applied in actual lifestyles paintings with right activity skillsets. Our studies paper for that reason formulates the inquiry of HR choice strictly primarily based totally on any other aspect that includes applicable enjoy as a critical variable for determination. For organizational practices and powerful choice primarily based totally on precedence Gilliland proposed that an approximate justice version additionally consists of the interplay of procedural and distributive justice and the connection of equity reactions to person and organizational outcomes. The procedural justice of choice structures is tested in phrases of 10 procedural guidelines, in which the delight and violation of those guidelines offer the idea for equity reactions. Distributive justice of hiring choices is tested with admire to equity, equality, and needs.

Proposed Model - The research focus is primarily initiated towards service-based industry that stipulates the HR requirement in relation to service-oriented organizations in Bangladesh. Davidson et al. (2011) suggested that concerns relating to finding the skilled labor force with proper experience are of paramount importance in order to find out a skilled labor force.

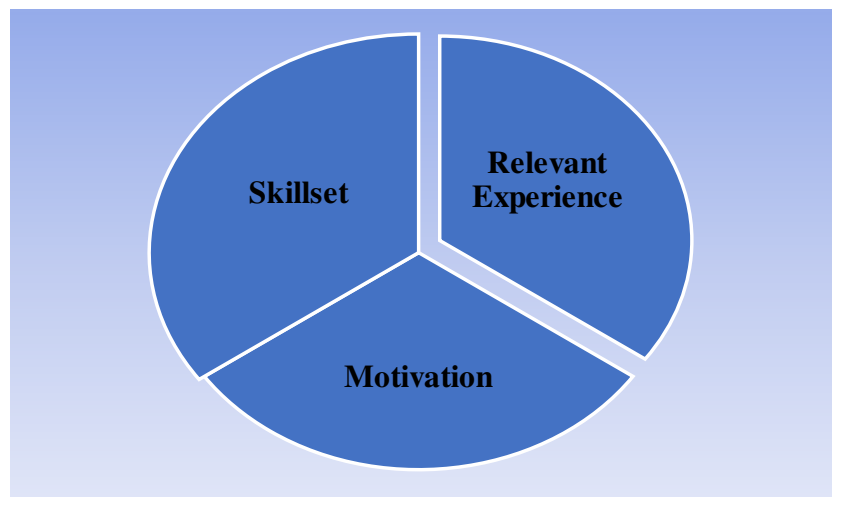

Fig 2: Selected variables.

Basak and Khanna, (2017) found that a defined HR policy helps make better decision in terms of $\mathrm{HR}$ selection processes. In order to conduct our research process properly we confined that to allocate various examples of service-based industry in Bangladesh we made random selection of some popular serviceoriented industry and how they perform various tasks.

In order to conduct our research process profoundly and effectively, we have conducted surveys to the employees in the following industries those are highly service specific.

1) Food Panda Delivery Workers

2) LP Gas Marketers

3) FMCG Marketers

4) Digital AD Campaign Development Team

5) Web Design \& Develop Team

6) Retail Market Data Analyst

In order to make the research process successful, we have reorganized our survey purely for the purpose of skillset test and relevant experience requirement test that was a standard guideline provided by United Nations Development Organization and European Union. In our survey we planned to initiate mostly relevant questions as suggested by the research questionnaires generated in order to subjectively identify the best possible employees for the organization from the selection process through evaluative quantitative processes. As our research process is profoundly following important unsupervised learning method that uses the $\mathrm{k}$ nearest neighbor algorithm hence it could be said in relevance to making employee selection process would remain unbiased as it would purely depend on expert suggestion analysis. Through our proposed model for application it's seen that all the three features are important for a successful career for any employees.

The best justification actually arises from this questionnaire in terms of that employee's quality attribute and how much he scores in all of the designated features. Through, amplified justification and core study of employee relationship with all the three attributive factors, defines how the employee performances were related towards job motivation. In the designed survey the result between motivation questions and overall work performance results to create an effective share of affect a motivated employee can create to work performance. Similarly other attributes play the equivalent role. Harvey, (2000) suggested that flexible 
organizations need empowering employees which in turn requires transformative and empowering learning.

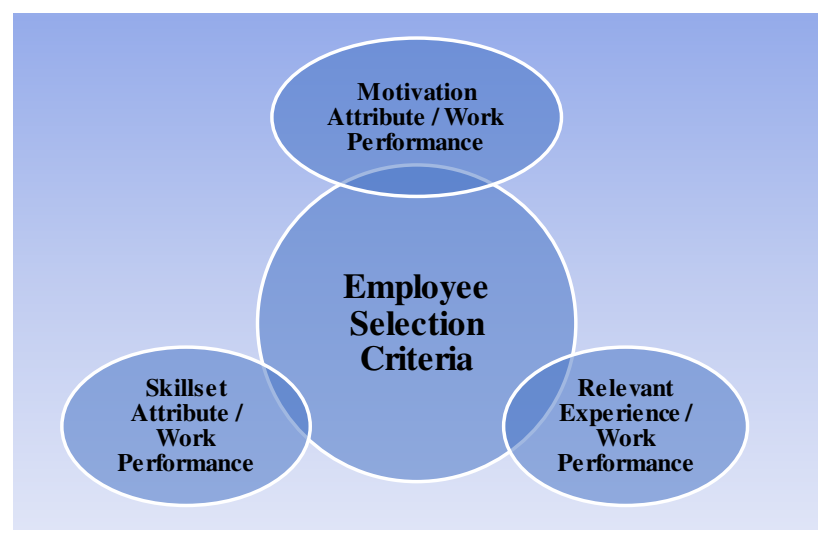

Fig 3: Selection criteria.

In accordance to Wright et al. (2002), it found that employee attitudinal commitment and job performance is none linearly dependent on employee tenure. It's seen that the findings are not observant across the supervisory or self-type performance measures. According to Wade \& Parent, (2002), it seen that for technical work place skillset requirement weighs more than half in comparison to motivation and relevant attribute in response to the sample size for more than 850 employees. In reference to this research process, the organizations were relentless in providing the exact weightage attributes suggested by the SME (Subject Matter Expert's) for each process chain operations. In Service model thus in accordance to industry survey we have determined an allocative weightage separation denoted by 2018 BBS - BLS report for skillset, motivation attribute and relevant experience requirement. The 2017-18 BBS-BLS Survey in Bangladesh has governed the following percentages as weight matrix for importance allocation in reference to job performance Table 1.

Table 1: Survey Questionnaire for Employee Performance Measurement by Employers

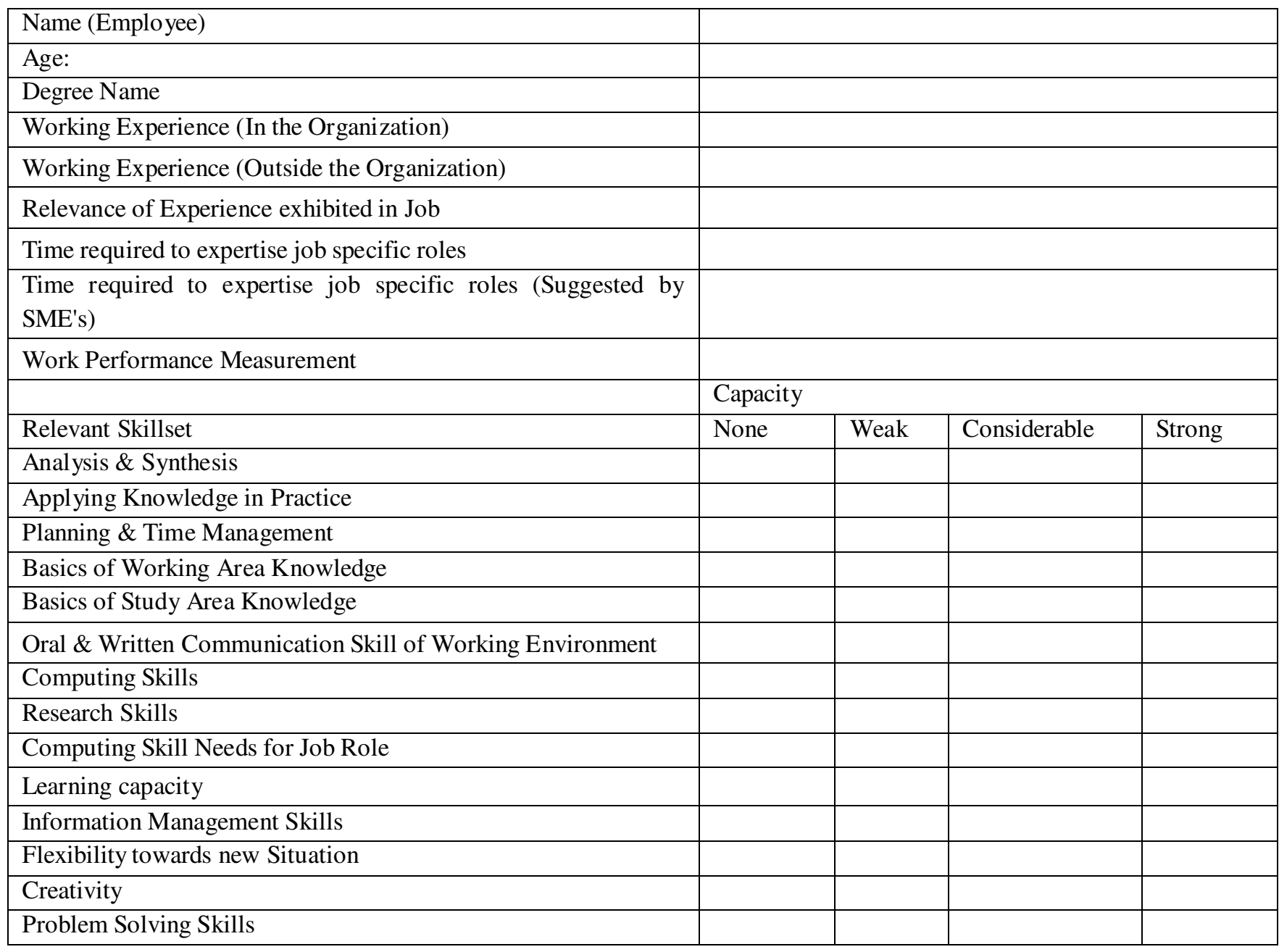




\begin{tabular}{|l|l|l|l|l|} 
Decision Making Skills & & & \\
\hline Team work Coordination & & & & \\
\hline Interpersonal Skills & & & & \\
\hline Leadership & & & & \\
\hline Working Ability in an Interdisciplinary Team & & & & \\
\hline Communication Ability with Non-Experts & & & & \\
\hline Problem Explanation Ability & & & & \\
\hline Appreciation of Diversity \& Multiculturism & & & & \\
\hline Autonomous Working Quality & & & & \\
\hline Initiative \& Entrepreneurial Spirit & & & & \\
\hline Ethical Commitment & & & & \\
\hline Quality Concern & & & & \\
\hline Success Willingness & & & & \\
\hline
\end{tabular}

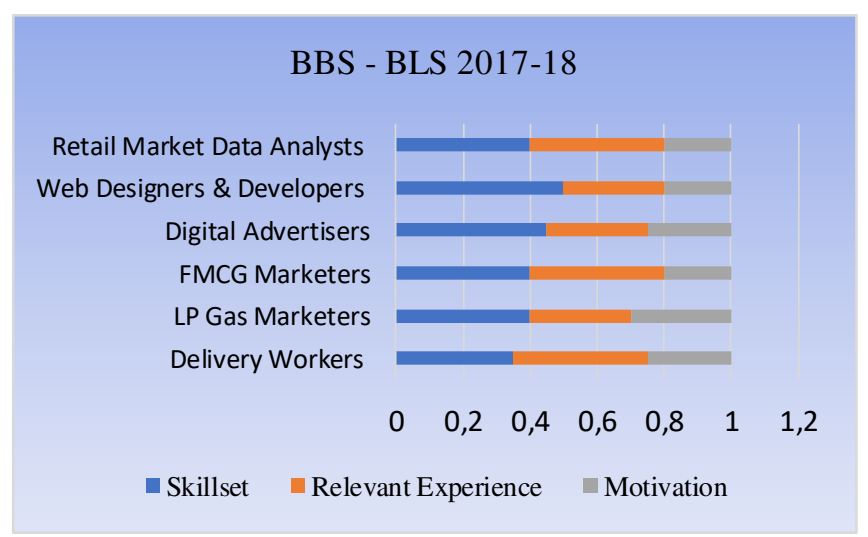

Fig 4: (BBS - BLS 2017-18)

Research Process Design - In order to conduct the research process, we have the conducted the survey on different service providers. Ideal weight allocations provided by BBS - BLS Survey are then compared with each of skillset, relevant experience and motivation attribute in order to determine the most suitable candidates for the job. The results of such hiring process would then be analyzed with organizational performance attributes in terms of revenue generation and customer satisfaction attainment.

\section{METHODOLOGY:}

This research process has included following sample sizes of variant service holder groups.

Sample Size - In order to conduct our research process adequately and effectively, it was very important that most of the survey subjects were answering the questioned remaining unbiased so that importance factor for each survey remains effective. Our Quantitative studies technique is absolutely reliant upon KNN Clustering approach so one can decide the nice UniversePG I www.universepg.com viable worker elegance for the choice technique. Conducted studies might hence generate the nice viable worker elegance thru similarly advanced schooling technique plan adjusted below the studies technique. The basic end result can be eventually mentioned on the stop so one can recognize the efficiency of the studies technique.

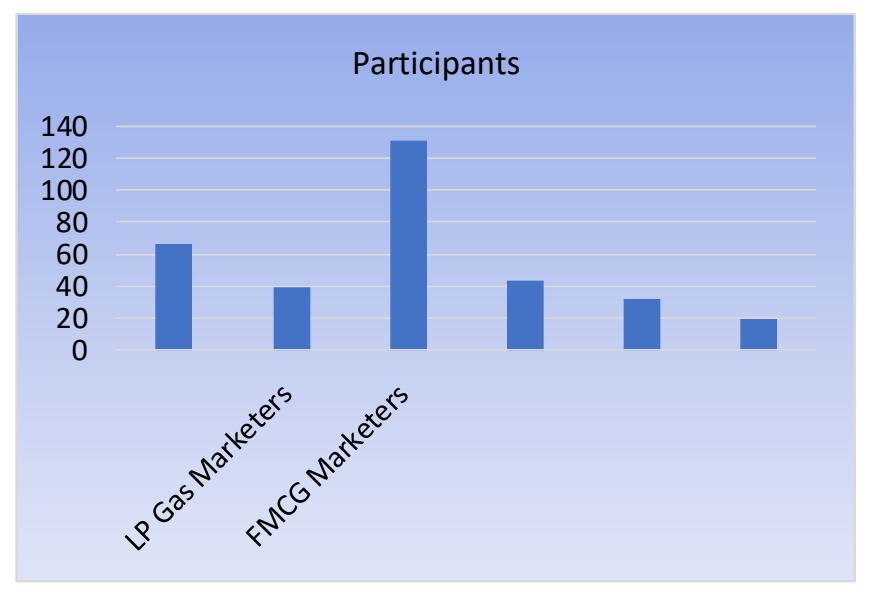

Fig 5: Participants.

K-NN (K Nearest Neighbor) Clustering - It's a category and regression method that is composed of choosing variables favorable to the $\mathrm{K}$ nearest variable most of the dispensed dataset. In ok-NN category, the output consequences to a category membership. The item receives categorized with the aid of using a plurality vote of its neighbors, with the ok notified item being assigned to the elegance maximum not unusual place amongst its ok nearest neighbors (ok is a nice integer, normally small). When $\mathrm{k}=1$, then the item is definitely assigned to the elegance of that unmarried nearest neighbor. In connection with regression evaluation for futuristics prediction, the 
output is referred because the belongings fee for the item. This fee is the common of the values of ok nearest neighbors. In our studies hassle, we look at that, there are a couple of attributes gift as dataset values for every criterion of skillset, applicable revel in and motivation factor. KNN on this studies approach is the answer technique of answering the query of studies hassle, which indicates if a statistics factor is a great deal similarly away or near the $\mathrm{K}$ statistics factor this is the supposed high-satisfactory placing characteristic of decided on worker for the job. Here K statistics factor is the factor of Interest. So, the Successful variable might be

Best Point of Interest $=$

$\operatorname{Min}(\mathbf{A B S}(\mathbf{X i} / \mathbf{Y i} / \mathbf{Z i}-\mathbf{K}(\mathbf{X}, \mathbf{Y}, \mathbf{Z})))$

In our studies hassle $\mathrm{K}(\mathrm{X}), \mathrm{K}(\mathrm{Y})$ and $\mathrm{K}(\mathrm{Z})$ will be the nice blend of a worker who has the maximum optimal overall performance degree in coherence to the maximum best worker cautioned with the aid of using the professionals (Alsuliman and Elrayah, 2021). Our studies proposition might lure that every of those elements might be evaluated as following variables.

$\mathrm{Xi}=$ Skillset Attribute of Employee

Mod X = Standard Skillset Attribute of Employee

Suggested with the aid of using BBS-BLS DataSource

$\mathrm{Yi}=$ Relevant Experience of Employee

Mod Y = Standard Relevant Experience of Employee

Suggested with the aid of using BBS-BLS DataSource

$\mathrm{Zi}=$ Motivation of Employee

Mod Z = Standard Motivation of Employee Suggested with the aid of using BBS-BLS Data-Source

$\mathrm{W}(\mathrm{i}, \mathrm{x})=$ weightage of skillset significance for a job

$\mathrm{W}(\mathrm{i}, \mathrm{y})=$ weightage of applicable experience in significance for a job

$\mathrm{W}(\mathrm{i}, \mathrm{z})=$ weightage of motivation significance for $\mathrm{a}$ job

The weight allocation technique will be very without problems decided thru allocation of distribution through BBS-BLS Data

Source: $2017-18$. Its visible that

$\mathrm{W}(\mathrm{i}, \mathrm{x} / \mathrm{y} / \mathrm{z})=\mathrm{w}(\mathrm{x}) / 1$ or $\mathrm{w}(\mathrm{y}) / 1$ or $\mathrm{w}(\mathrm{z}) / 1$

The applicable BBS-BLS Data

UniversePG I www.universepg.com
Source: $2017-18$ might offer the precise qualification characteristic necessities cautioned with the aid of using the SME's, organizational professionals, technique professionals and manufacturing professionals guiding principle to decide organizational overall performance factor.

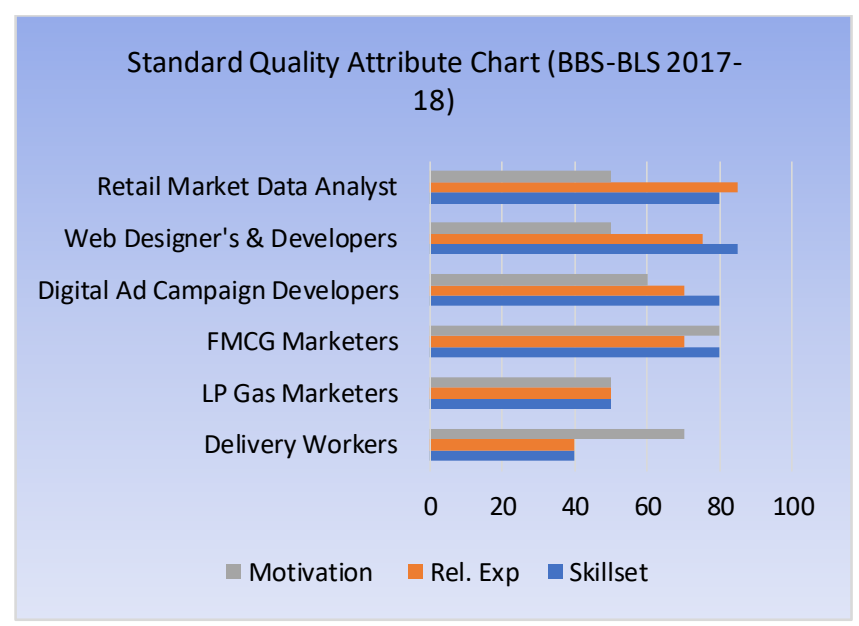

Fig 6: Quality chart.

Step-wise Research Process:

1) Conduct the Survey.

2) Answers being marked

3) Obtained Marks in

a) Skillset

b) Relevant Experience

c) Motivation

4) Applying best allocation weights with each selection factors and obtaining a final mark for the prospective employee.

5) Applying best allocation weights with each selection factors and obtaining a final mark for the best employee (in accordance to skillset attribute suggested by SME, Organizational Experts, Process Experts)

6) Applying the KNN Algorithm in order to determine the best performer among the prospective employees for final selection.

Through KNN algorithm we would discover the best employee under the following criteria.

\section{Best Employee for Selection will be:}

$\operatorname{Min}(\operatorname{ABS}(K(X i, Y i, Z i)-K(\operatorname{Mod}$ X, Mod Y, Mod Z)) $)$

Where,ABS refers to absolute value

$\mathrm{K}$ (Xi, Yi, Zi) determines the ultimate weighted quality attribute of prospective employee and 
K (Mod X, Mod Y, Mod Z) determines the ultimate weighted quality attribute of best employee. Min refers to the selection of an employee with least difference in quality attribute in compassion to the best employee. The minimization refers to the choice of best employee under the selective factor of least difference in between the best employee quality and prospective employee quality.

\section{RESULT AND ANALYSIS:}

A sample example has been derived from KNN classification process where the employee with the least possible difference with best performing employee in accordance to the suggestion derived through selection process has been selected. Our research process has thus conducted a much evaluative guess for best employee selection. Among the various organizations who have adopted such a policy during the COVID 19 pandemic in order to strengthen their business operation have found immense benefit in their organizational performance.

\section{Employee Selection by KNN}

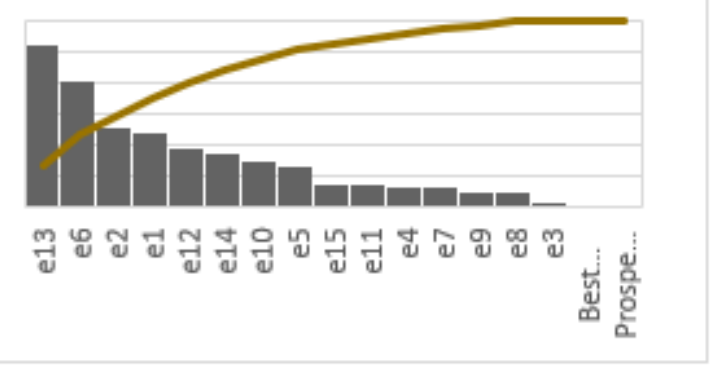

Fig 7: Sample employee selection.

During Covid 19 pandemic, it's seen that there were obvious challenges in the entire world about depending on soft skills and more AI driven jobs (Bessen, 2018). Hence there was big demand of job whereas prospective employment opportunity dropped much further, within the relevant effect of COVID 19 (Borjas\& Cassidy, 2020). It's found that online based Supply chain businesses gained the maximum exposure and client requests in reference to business needs and growth opportunities (Arecher \& Rand, 2021). In order to make the business process effective and sustainable with newer global challenges, few servicebased industries had undertaken an exclusive measure to apply KNN based Employee selection in terms of fulfillment towards changed customer demand. Due to COVID effect and already in demand pressure of AI driven job industry had fallen a bigger prey to job loss and unemployment. It's seen that (TBS-November 2020) all the service industry despite of COVID had seen huge surge in rise of job application.

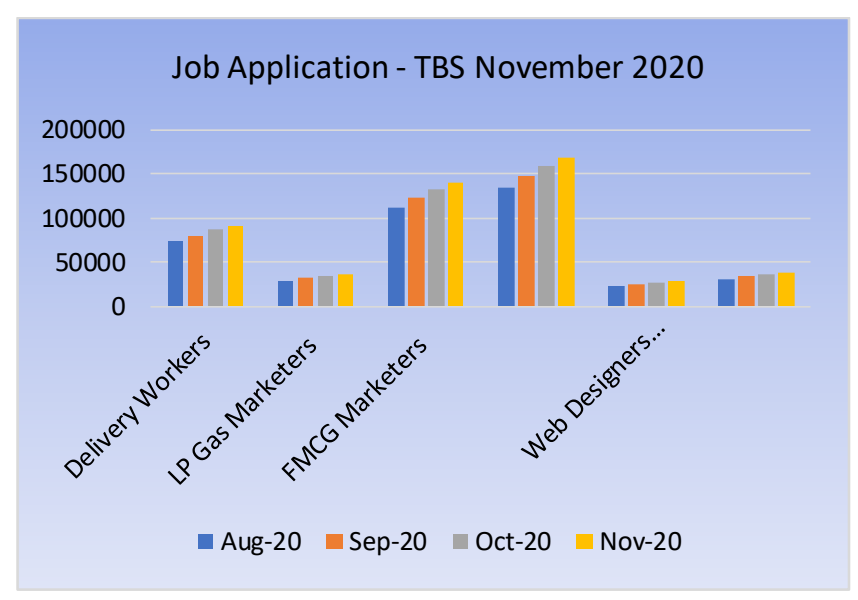

Fig 8: TBS job demand rise.

In order to make the best choice of employee selection who would become beneficial for the organization, various industries adopted this KNN based selection model in terms of suggestions provided by the industry experts. It's seen that various organizations have performed extremely well through cost management and asset turnover margin through the specific quarter of following this hiring principle.

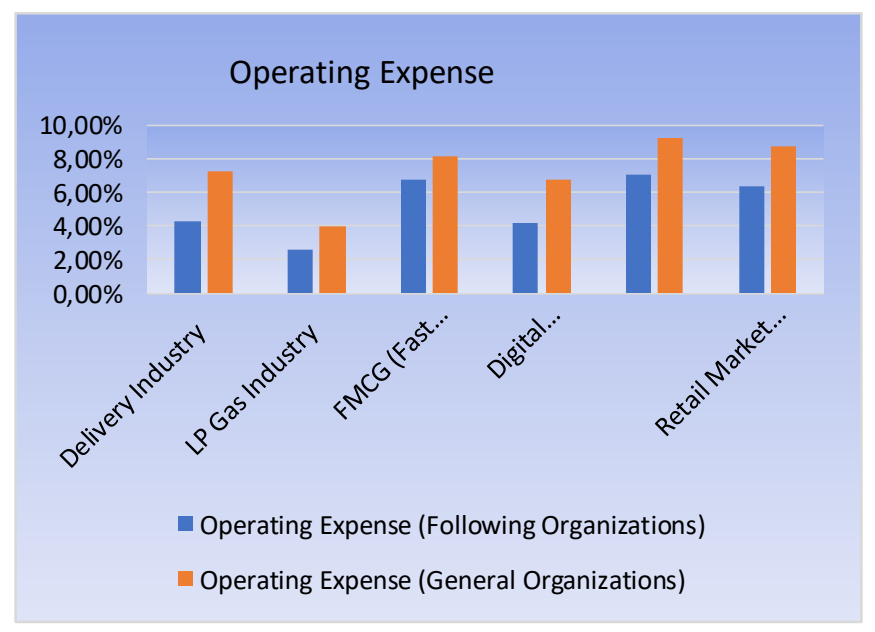

Fig 9: Operating Expense Compare

In accordance to overall analysis it's seen that all the organizations that followed $\mathrm{KNN}$ based selection methods for employee selection have performed well for the last quarter of 2020. Organizations have poten- 
tials referring to their selected employee bias and validation criteria.

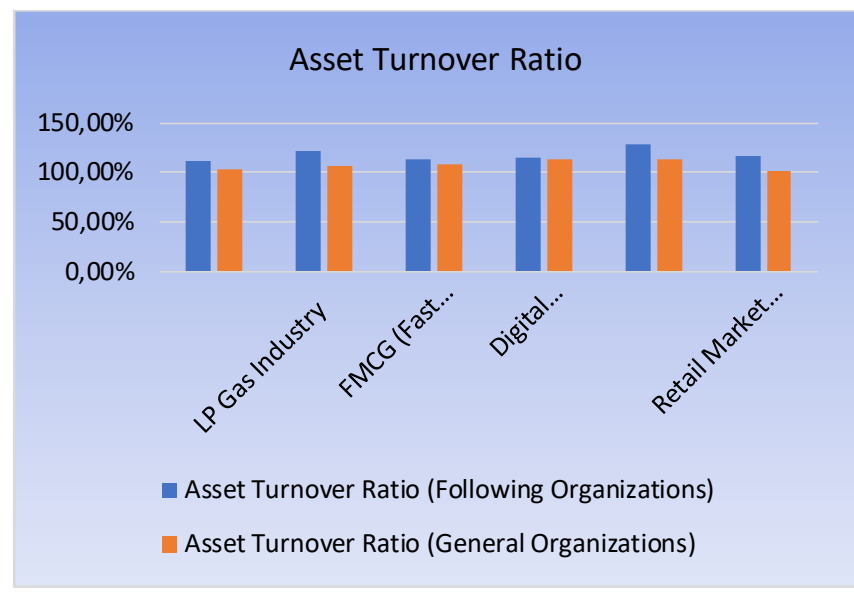

Fig 10: Asset turnover ratio compares.

\section{CONCLUSION:}

The overall research process is highly dependent on the independent variable termed as expert suggestion, process experts' opinion, SME (Subject Matter Expert) suggestion. The complete work process is highly challenging and with development of time mots work process faces a certain degree of change in work application and completion process. Automation and technology are changing work completion process every day (Aguinis et al., 2005). Hence all the suggestions provided in light of solution experts might not be the best suggestions for employee selection but they certainly are better than generic methods of selection. There are much further issues that could discussed as a betterment method to make effective suggestions. The research process didn't include any effective process application that confirms the HR development and reduction issues as associative suggestions for $\mathrm{HR}$ selection. Our research process finally has been capable to clearly conclude the following tasks: Evaluate Expert Opinions to Identify Effective \& Efficient HR for any industry, Unbiased Method to suggest the best choice for an organization, Best Possible Skillset, Experience \& Motivation Attribute for any given industry, Defined organizational benefit in terms financial performance.

\section{ACKNOWLEDGEMENT:}

This research paper is the completely data dependent hence, all the theoretical aspect could only be proved

UniversePG I www.universepg.com by the data provision help from Bangladesh Bureau of Statistics - Labor Survey Division - (2017-18) team for their continuous and ample support. In order to maintain organizational privacy various organizations who participated in this survey through their effective contribution by providing employee details remaining anonymous should also get highest commendations and affirmative condolences. The final recommenddation for acknowledgements should go to the researchers without which this ultimate result achievement would have been impossible.

\section{CONFLICTS OF INTEREST:}

We declare no single potential conflict of interest.

\section{REFERENCES:}

1) Agbo M. U, Ayogu D. U, (2015). The Analysis of Human Resources Development as a Critical Factor on Organizational Productivity, The International Journal of Academic Research in Business and Social Sciences. 5(9), 2015.

https://www.iiste.org/Journals/index.php/PPAR/ article/view/25791

2) Aguinis, H., Beaty, J. C., Boik, R. J. \& Pierce, C. A. (2005). Effect Size and Power in Assessing Moderating Effects of Categorical Variables Using Multiple Regressions: A 30-Year Review. Journal of Applied Psychology, 90(1), 94-107. https://doi.org/10.1037/0021-9010.90.1.94

3) Aguinis, H., \& Smith, M. A. (2007).Understanding the impact of test validity and bias on selection errors and adverse impact in human resource selection. Personnel psychology, 60(1), 165-199.

4) Alsuliman BRA, and Elrayah M. (2021). The Reasons that affect the implementation of HR analytics among HR professionals, Can. J. Bus. Inf. Stud., 3(2), 29-37.

https://doi.org/10.34104/cjbis.021.029037

5) Arecher \& Rand, (2021). Tucking in the time of COVID, Behavior Research Methods. Access 94.

6) Basak A. Khanna K (2017). A Study on the Selection Criteria of Different Hotels of Delhi NCR in Accordance to the HR Policies and 
Market Trends, International Journal of Social Sciences and Humanities, 1(1), 27-38. https://doi.org/10.29332/ijssh.v1n1.13

7) Becker, B., \& Gerhart, B. (1996). The Impact of Human Resource Management on Organizational Performance:Progress and Prospects. Academy of Management Journal, 39(4), 779-801.

8) Bessen, J. (2018). AI and Jobs: the role of demand Borjas G. \& Cassidy H. (2020). The Adverse Effect of the COVID-19 Labor Market Shock on Immigrant Employment.

9) Davidson, M. C. G., \& Wang, Y. (2011). Sustainable Labor Practices? Hotel Human Resource Managers Views on Turnover and Skill Shortages. Journal of Human Resources in Hospitality \& Tourism, 10(3), 235-253. https://doi.org/10.1080/15332845.2011.555731

10) Gault, J., Redington, J., \& Schlager, T. (2000). Undergraduate Business Internships and Career Success: Are They Related? Journal of Marketing Education, 22(1), 45-53.

11) Gault, J., Leach, E., \& Duey, M. (2010). Effects of business internships on job marketability: the employers' perspective. Education + Training, 52(1), 76-88. https://doi.org/10.1108/00400911011017690

12) Gilliland, S. W. (1993). The Perceived Fairness of Selection Systems: An Organizational Justice Perspective. Academy of Management Review, 18(4), 694-734.

13) Goldstein, H. W., Zedeck, S. \& Goldstein I. L. (2002). Is This Your Final Answer? Human Performance, 15(1-2), 123-142.

https://psycnet.apa.org/record/2002-13451-007

14) Grosse, E. H. \& Glock, C. H. (2015). The effect of worker learning on manual order picking processes. International Journal of Production Economics, 170, 882-890. https://doi.org/10.1016/j.ijpe.2014.12.018

15) Gupta P, David J. B, Jaime S. S. (2010). An Exploration of Student Satisfaction with Internship Experiences in Marketing, Business Education \& Administration, 2(1), pp. 27-37, 2010.

16) Harvey, L. (2000). New realities: The relationship between higher education and emp- loyment. Tertiary Education and Management, 6(1), 3-17.

https://doi.org/10.1080/13583883.2000.9967007

17) Hoque MT, Alam J, Burman SD, and Alam QN. (2020). Impact of macroeconomic and bank specific variables on spread of interest rate: a study of listed commercial banks in Bangladesh, Can. J. Bus. Inf. Stud., 2(6), 148156.

https://doi.org/10.34104/cjbis.020.01480156

18) Liang-Chih Huang, Kuo-Shu Huang, HsiuPing Huang, \& Bih-Shiaw Jaw. (2004). Applying fuzzy neural network in human resource selection system. IEEE Annual Meeting of the Fuzzy Information, 2004.Processing NAFIPS '04.

19) Mika, S., Ratsch, G., Weston, J., Scholkopf, B., \& Mullers, K. R. (1999). Fisher discriminated analysis with kernels. Neural Networks for Signal Processing IX: Proceedings of the IEEE Signal Processing Society Workshop (Cat. No.98TH8468).

https://ieeexplore.iee.org/document/788121

20) Ramstad Peter M, Boudreau John W. (2004). Talentship and human resource measurement and analysis: from roi to strategic organizational change, CEO publication. G 04-17 469

21) Singer, M. S., \& Bruhns, C. (1991). Relative effect of applicant works experience and academic qualification on selection interview decisions: A study of between-sample generalizability. Journal of Applied Psychology, 76(4), 550-559.

https://doi.org/10.1037/0021-9010.76.4.550

22) Swanson R.A (1995). Human Resource Development: Performance Is the Key. Human Resource Development Quarterly, Jossey Boss Publishers, 6(2), 207-213. https://doi.org/10.1002/hrdq.3920060208

23) Truxillo, D. M., Steiner, D. D., \& Gilliland, S. W. (2004). The Importance of Organizational Justice in Personnel Selection: Defining When Selection Fairness Really Matters. International Journal of Selection and Assessment, 12(1-2), 39-53. 
24) Tsai H.T., Moskowitz H. \& Lee L.H. (2003). Human resource selection for software development projects using Taguchi's parameter design. European Journal of Operational Research, 151(1), 167-180.

https://ideas.repec.org/a/eee/ejores/v151y2003i1 p167-180.html

25) Uddin N, Md Siraz Miah \& Raihan Hossain (2013). Discriminant Analysis as an Aid to Human Resource Selection and Human Resource Turnover Minimization Decisions. International Journal of Business \& Management; 8(17); 2013.

26) Voca Z., Havolli Y. (2019). The Impact of Human Resources Development on Small and
Medium Enterprises (SMEs) Performance: The Case of Kosovo Journal of Economics and Management Sciences; 2(2); 2019. https://doi.org/10.30560/jems.v2n2p45

27) Walker A.J. (1993). Reshaping the human resource function with technology, Handbook of human resource information systems, New York, McGraw-Hills.

28) Wright, T. A., \& Bonett, D. G. (2002). The moderating effects of employee tenure on the relation between organizational commitment and job performance: A meta-analysis. $J$. of Applied Psychology, 87(6), 1183-1190.

https://doi.org/10.1037/0021-9010.87.6.1183

Citation: Sami HM. (2021). Optimizing organizational overall performance, the use of quantitative choice of HR in carrier quarter enterprise of Bangladesh, Can. J. Bus. Inf. Stud., 3(3), 49-59. https://doi.org/10.34104/cjbis.021.049059 @ @ 